\title{
STRUCTURAL STUDIES ON SOUTHWESTERN
}

\author{
CACTACEAE. \\ CARLETON E. PRESTON. \\ (WITH NINE FIGURES)
}

Tнат the Cactaceae, a family in every respect appearing to be of recent origin, are unique in the extent of their adaptive modifications to arid conditions is a commonplace. Not only does this adaptation affect the external parts as gross structures, but in still greater measure does it work changes upon the minute anatomy by modifying the histological elements. These internal changes, keeping pace with and supplementing the external, raise this family to the first rank among the desert plants. A critical study of the minute anatomy from the standpoint of ecology, therefore, should be most fruitful. Moreover, since the family is one of late origin, in which definite groups have so far not crystallized out, but between which nearly all connecting links are present, a general comparative examination of internal structure should afford at least some further clue as to the lines upon which the various groups have developed or are still developing, adding to or confirming the evidence already obtained from the study of external characters.

Viewed from the standpoint of the systematist, this paper, being a study of the general histology of eight southwestern forms, can by itself be of little value, serving only as an addition to the number of species already critically examined. Although in collecting the material for study it was my intention to choose such forms as could be considered typical, I found, as work went on, that too much variation occurs to admit of their use in this way except upon the broadest lines. In order to do complete and satisfactory systematic work on the basis of structural characters, evidently one would have to compare, not only all the genera within the family, but at least the larger subdivisions and I901] 
the doubtful species in each genus. The single genus Cereus contains a multiplicity of forms, the structures of which must be very diverse. How are these related, and what are their several connections with the other genera? Does the gradual change in internal structure agree with the external and strengthen the validity of the various systematic groups as now recognized? Schumann ${ }^{x}$ has pointed out that the original ancestor of the Cactaceae was probably something like Peireskia. Ganong ${ }^{2}$ has followed up and confirmed the relation between this genus and Opuntia, chiefly on the basis of external characters. What are the steps by which the corresponding internal structure has changed? Schumann ${ }^{x}$ has hinted rather strongly at the connecting links between Opuntia and Cereus; anatomical studies may give more definite information upon this point.

This paper seeks to impress the importance of careful structural study to help out the ordinary work on external characters, to point out the general trend of evolution exhibited, and to interpret certain anatomical conditions upon a physiological basis.

As regards environmental adaptation, next to diminution of surface and other modifications to lessen transpiration, the storage of water is most important. The turgor exhibited in many of the more succulent forms is surprising. Especially is this the case in the younger portions of the arborescent species, and throughout the interior of those which are low and cespitose, where for a long time turgor alone is sufficient to sustain all the weight placed upon it - in other words, to preserve the rigidity of the plant. Hence there is no necessity for a strong vascular system; in fact, its room is more valuable than its presence, and we find in general that the vascular system is of late development, and in low forms almost never reaches a high state of perfection. The component elements also are oftenest of a kind generally considered primitive, showing an apparent retrogression, but one which in many cases is complicated by the

'Gesammtbeschreibung der Kakteen. I897.

${ }^{2}$ Beiträge zur Kenntniss der Morphologie und Biologie der Kakteen. Fiora $79: 49-86$. I 894 . 
addition of adaptive modifications. This is true particularly in the first form examined, Cereus Fendleri, of cespitose habit, and one of the most succulent. Upon cutting a shoot transversely one will notice that the bundles recede into the tissue for some distance, both in the severed portion and in that remaining on the plant, while the parenchymatous tissue still remains turgid. It is thus easily demonstrable that the bundles are normally under great tension. The mechanical arrangement by which such elasticity is rendered possible will be found in the structure of the xylem. Another point of interest, probably of value upon systematic grounds, is the behavior of the bundles in the matter of secondary medullary ray formation, development of interfascicular cambium, and anastomosis.

Before considering the various forms separately, there are certain points of structure which can best be mentioned in general. Schumann, both in his monograph and in Engler and Prantl's Pflanzenfamilien, gives an idea of the ordinary structure of the group. A condensed account is also given by Ganong 3 which I take the liberty to quote as a basis for the following discussion.

As to the tissues, it is enough here to say that the characteristic xerophilous appearances are a strong cuticle, thick epidermis, perfect cork, sunken stomata, collenchymatous hypoderma, deep palisade layers, great development of pith and cortex, which consist of large, round, splendidlypitted water-storing cells, often containing mucilage; a fibrovascular system, in general simple in its make-up, lacking annual rings, composed as to its xylem of strongly-ringed and spiraled tracheids, which are often collected into gland-like masses, the whole system conforming closely to the external form and following its morphological changes.

Regarding the character of sunken stomata and their relation to hypoderma slight comment is necessary. The stomata are not sunken in the sense of having deep-lying guard cells; on the contrary, they are well upon the surface, as Schumann notes. Whatever vestibule there may be is of a different nature. With the increase in thickness of hypoderma an interval is produced

3 Recent problems in the anatomy, morphology, and biology of the Cactaceae. Bот. Gaz. 20 : I 30. I 895. 
between the assimilative tissue and the guard cells. Through this collenchymatous tissue run canals connecting the two; these canals must at all times be filled with water vapor, and probably act in a much more effective manner than would an equally large external vestibule. The hypoderma is of varying thickness, of one cell layer only in some species of Mamillaria, of seven to ten in certain other forms, as in Cereus giganteus. There appears to be no difference in the character of the cells in the various groups; the walls are irregularly thickened, the thin portions allowing osmotic transfer of materials between the cells, and from them to the epidermis. Portions of hypoderma are shown in figs. $I-3$.

With respect to assimilative tissue, Ganong speaks of deep palisade layers. Schumann, on the other hand, says that the cells are not in palisade form, but spherical. In point of fact, there seems to be considerable variation in this regard. In no form which I have examined have I found an assimilative tissue of absolutely spherical unmodified cells. There has always been an elongation perpendicular to the surface, sometimes slight, as in Opuntia leptocaulis, in other cases very well-marked, as in Echinocactus Wislizeni. There is also a general compacting of the tissue in this region. These elongated cells extend inward in the form of more or less definite chains or filaments, grading rather slowly into the ordinary parenchyma tissue, which in many cases contains chlorophyll in some quantity, in others is colorless. In the latter instance the chlorophyll, as noted with the naked eye, seems confined to a well-marked rind.

It is perhaps only fair to suggest that environment may have a considerable influence upon the development of the palisade form in this family, as well as in those which possess functional leaves. The classical works of Stahl, Pick, and other investigators leave little question but that the elongation of the assimilative tissue, at least in some degree, is in direct response to the stimulus of light. The habitat of the plants here described and contrasted is one marked for its great light intensity, which, as I have found from a rather comprehensive examination of foliar 
structures, leaves its imprint upon the arrangement and development of assimilative tissue in almost all cases. Schumann's statement that the assimilative cells are spherical may be true of the plants when a general average is taken, including epiphytic types, and others growing under entirely different light conditions. Possibly also the effects of artificial cultivation may have some place in his results.

The medulla in many cases is of thick-walled and pitted cells, as Ganong describes, but this is by no means universal, often varying within the limits of a genus as now established. The cells are often exceedingly thin-walled and have no need of pits to maintain connection between them. The presence in this tissue of mucilage, crystals, etc., is likewise variable with the species, and needs separate discussion. Not only do the crystals vary in distribution to a wide extent, but also in relative frequency, some species being far richer in this deposit than others of the same habitat, a fact which, it seems
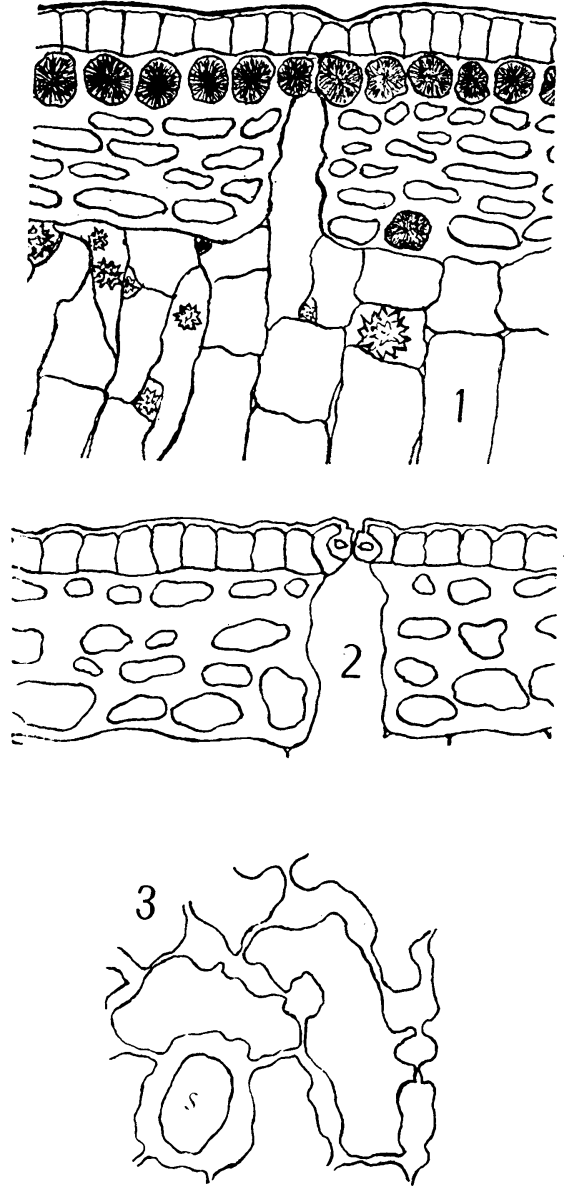

FIG. I.-Epidermis and hypoderma of Opuntia arbuscula; opening of stoma does not show, owing to slightly oblique character of section.

FIG. 2.-Epidermis and hypoderma of Cereus Fendleri in section, showing stoma.

FIG. 3.- Hypoderma of Cereus Fendleri, seen from inside, showing character of walls and opening of stoma canal $(s)$. to me, can only be referred back to the varied selective power of roots for chemical solutions. 
The particular value of Ganong's terse and concise description of the fibrovascular system lies in the last clause, "the whole system conforming closely to the external form, and following its morphological changes." Upon this fact depends the usefulness of internal structure as evidence of systematic value, a point which this writer thus recognizes, and one which I feel that I cannot too strongly insist upon. Schumann gives a slightly fuller account of the vascular system, noting the presence of annular and spiraled ducts, especially in young bundles, and their subsequent replacement by the various tracheids. This is also the statement of the fact that a regression toward more primitive conditions is taking place, by the substitution of elements of a less highly developed character. In this particular especially considerable variation is shown, offering, together with the methods of bundle-branching and anastomosis, a very fruitful field for research from a systematic point of view. Annual or periodic rings are not always absent, as will be shown; in fact, in one form I have examined they are peculiarly marked.

The work presented in this paper was done on fresh material collected in the vicinity of Tucson, Ariz., during December I900, and examined immediately at that place. Opportunity was thus given to study the plants in their natural habitat, a very valuable advantage in dealing with physiological phenomena.

Cereus Fendleri Engelm.-The hypoderma is comparatively thin, of about three layers of cells; the cuticle is thick as usual; there are no crystals in the epidermis, only an occasional one occurring in the deeper cells of the hypoderma. The assimilative cells are large and fairly elongated, those nearest the surface containing the most chlorophyll, those toward the center grading into a very thin-walled parenchyma also slightly chlorophyllous, and filled with an intensely stringy and slimy mucilage, which, by taking stains readily and by preventing dehydration, renders any delicate manipulation of sections upon fresh tissues out of the question. It is by this means that the plant is able to hold water so persistently. In the parenchyma are imbedded the bundles, slightly separated from each other in most cases, 
but with some anastomosing. The lateral branches, which apparently start for the tubercles, break up and form a network through the tissue. In this species the bundles appear to start in a definite circle in cross section, in contrast to the undulate line in which they occur in certain other forms. There seems to be no interfascicular cambium, the bundles in their exceedingly slow growth apparently pushing their way outward into the succulent tissue, compressing it about them, and taking up the room it formerly occupied, instead of the growth of the medullary tissue keeping pace with the increase of the bundles. The development of phloem is exceedingly slight, consisting wholly of sieve tubes and companion cells, with no trace of thick-walled elements.

Of the xylem more needs to be said. A bundle is represented in $f i g .4$. The elements which compose it are but two, spiraled ducts and tracheids

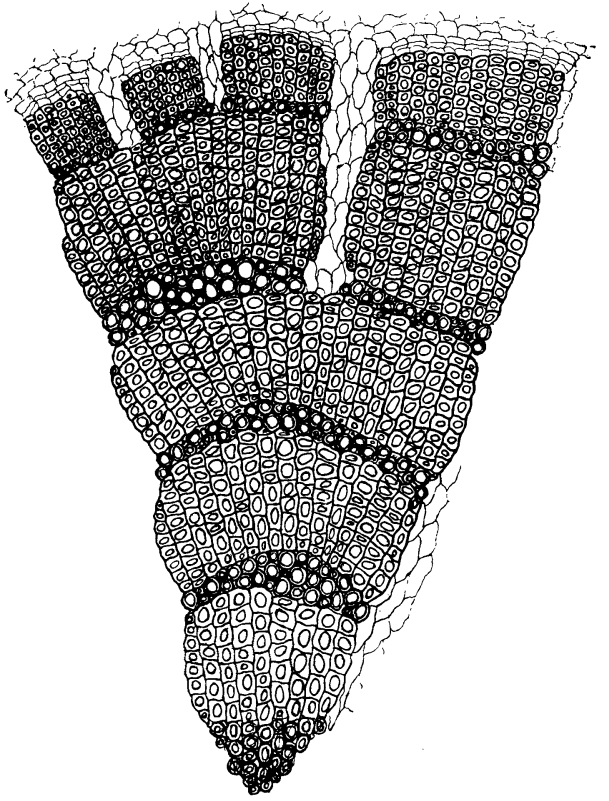

FIG. 4.--Xylem portion of stem bundle in Cereus Fendleri. with a peculiar flattened spiral, the latter being by far the more abundant. These alternate in time of development, showing what appear to be periodic changes. The very earliest portions of the xylem are composed of the ordinary spiraled ducts, irregular in size and position, and thereafter a small layer of these cells appears at what is probably the beginning of each season's growth. The flat spiraled tracheids, an element already mentioned by Ganong and Schumann, form in definite rows, each apparently the product of a single cambium cell, which, after cutting off the few irregular segments to form the spiraled ducts, apparently undergoes no more division by radial 
walls during the season. All the broadening of the bundles, therefore, occurs at the beginning of a period of growth. Likewise, when a branching is to occur, the resulting medullary ray appears at the beginning of the season, as shown in the drawing.

It seems likely that the flattening of the spiral in the tra-

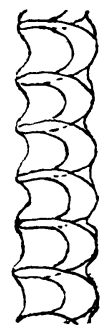

FIG. 5---Portion of tracheid of flattened spiral type from xylem of stem bundle in Cereus Fendleri. cheids, which compose most of the xylem, is what gives the elasticity so prominent in this bundle. Such a flattening inwards would allow a far greater stretching of the spiral than would be possible in the commoner round type. A fact which strengthens this assumption is that the walls of the tracheids in a preparation will be seen to be wrinkled between the spirals ( fig. 5). In the living condition those were in all probability perfectly straight, and the turns of the spiral at a greater distance apart.

Another point which can be deduced safely from an examination of the figure is with respect to periodicity of growth. From the comparison with the amounts of earlier years, it will be seen that the xylem for the season was about half formed at the time of collection of material. As this took place in the latter part of December, it seems probable that the season of growth in the southwest is limited by the summer drouth and intense heat, rather than by the winter cold.

The branching of bundles and formation of secondary medullary rays in the stem is not of common occurrence in the Cactaceae, so far as my investigation goes. In most of the forms to be described a different state of affairs will be noted. The bundles of the root, however, branch in the ordinary manner in all the species I have examined.

The absorptive root 4 of Cereus Fendleri has a cork four to six cell layers in thickness. Successive layers of this kind are formed, with parenchymatous intervals, so that the bark is being constantly shed in flaky fragments, and is with equal rapidity replaced. The cork cambium lies a short distance outside the

4 Bот. Gaz. 30: 348. 1900. 
secondary phloem of the bundles. This phloem is composed almost wholly of sieve tubes which, when examined January I, had no callus visible. Lateral plates occur in abundance, in addition to those at the ends of the cells.

The xylem has but two elements, at least in the secondary portions. The more prominent, and by far the more abundant of these, is the tracheid, with ellipsoidal pits in more or less regular lines, an element which, from the shape of the pits, hardly coincides with the ordinary scalariform vessel, as seen in Pteris, for instance, but which, for convenience, I shall here designate by that term. Though the separate cells are comparatively short, there is often a continuous passage through several (a transition stage toward the true trachea), the walls between the adjacent cells being partially dissolved, and represented by nothing more than a thick and distinct ring. The other element is the obliquely pitted fiber tracheid, which apparently supplants the ordinary wood fiber in the majority of the Cactaceae. ${ }^{5}$ The medullary tissue is but little compressed in the rays, giving a rather loose structure to the root as a whole. Crystals here, as also throughout the entire plant, are very few in comparison to their number in all the other species examined, occurring in the various parts of the parenchyma tissue, always in the aggregate form.

The anchoring root differs from the absorptive chiefly in the relative numbers of fibrous and vascular elements, as stated in a previous paper, ${ }^{6}$ in which the phrase " wood cells" was used by mistake for "fiber tracheids." There is also a slight difference in the amount of sieve tissue developed in the phloem, the greater amount belonging naturally to the absorptive root. In species where the two systems are not clearly differentiated, the elements are more nearly equal as regards amount of space occupied by each. As a rule, the only difference between the two roots is one of proportion of elements, not of their variety.

5 For a drawing of this element see Strasburger's Text-book of Botany, translated by Porter, $\mathrm{fg}$. $143 \mathrm{ft}$.

${ }^{6}$ Bot. Gaz. 30: 348. I900. 
The absorptive root, therefore, will be the only one taken under consideration in discussing the remaining forms, except in one or two special cases. The difference between the two is hardly as well marked in Cereus Fendleri as in Opuntia fulgida, to be mentioned later.

Echinocactus Wislizeni Engelm.-The epidermis and hypoderma are without crystals, the latter of six or seven layers of cells. The assimilative tissue is compact, with cells much elongated perpendicular to the surface, even in the sinuses between the ridges. The young parts do not develop chlorophyll in the sinuses until the ridges of tubercles, at first closepressed together, become separated. The chlorophyll in this form is confined to a definite rind of palisade-like cells, which on the inside changes somewhat abruptly to a colorless parenchyma, rather thick-walled and fitted with a splendid system of pits and openings. Within this tissue are occasional crystals. Mucilage does not seem to be abundant in this species, but its place is taken by a watery solution, especially prominent in parts still growing, which upon long exposure to the air causes the tissue to assume a pinkish tinge. The medullary tissue about the bundles contains a fairly large quantity of starch, greatest in amount and widest in distribution in the young portions.

The bundles, as seen in cross section in a young stage, are not in a perfect circle, but rather in a zigzag line ( $f g .6$, diagram), with alternate points and depressions. There seems to be no branching or secondary medullary ray formation, and but little increase in the width of the original bundles. The zigzag line does not appear to be entirely the result of bundles passing out of the tubercles, for nearly all of the bundles in section appear to be cut directly across when all are cut in the same plane. They anastomose to a considerable extent, and, taking as centers the bundle at the base of each inner depression, join together with it to form a complex wood structure. The direction of growth of the side bundles is slightly inclined toward the central one, bringing the xylem of the whole group into 
close contact at an early stage. The phloem portions, however, remain distinct for each bundle. By this slight divergence, considerable medullary connection is left between the pith and the thick layer of storage tissue outside the poorly developed bundle cylinder, a far greater connection than could occur with the usual distribution, thickening, and branching of bundles seen in dicotyledonous stems. This peculiar grouping will be noted

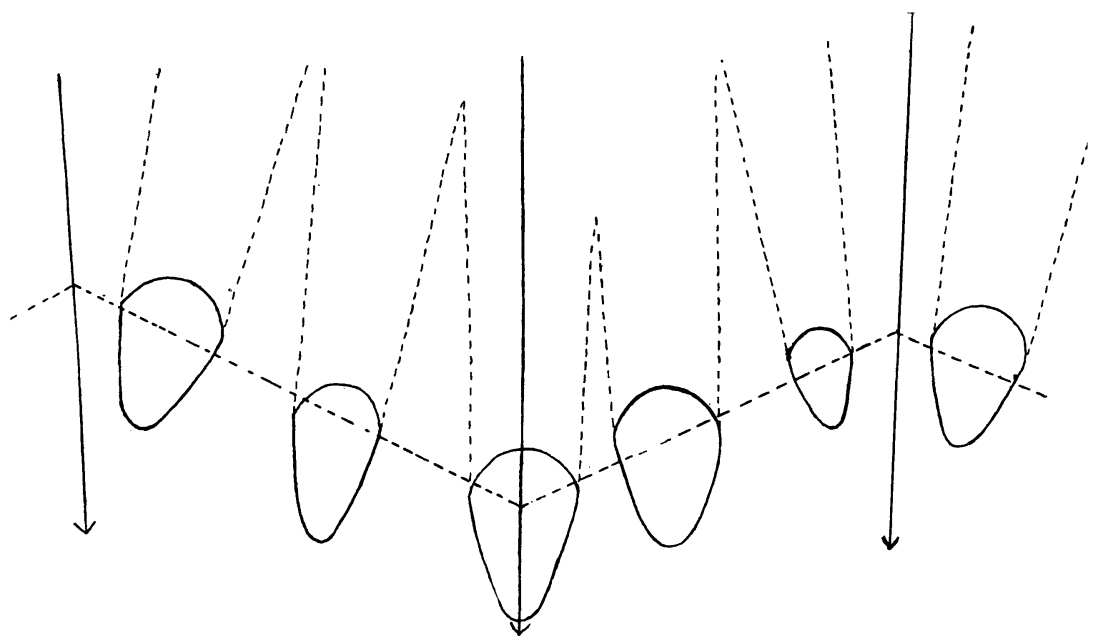

FIG. 6.--Diagram of position of bundles in Echinocactus Wisizeni and others.

in a far greater degree of perfection in Cereus giganteus, next to be described. Here, as there, there seems to be no anastomosis of these groups of bundles, the incipient wooden ribs. In Opuntia, on the contrary, where this anastomosis of bundles likewise occurs to some degree, a still further reticulation is found, in that the groups as units anastomose.

As regards more minute structure in E. Wislizeni, the phloem is composed mainly of sieve vessels, the outer of which, together with the adjacent parenchyma, are composed and rendered sclerenchymatous, forming a sheath, here separate for each individual bundle. The xylem, at least in later portions, is composed entirely of spiraled tracheids of uniform size, but not in definite rows, the spiral also being of the ordinary type. A 
certain amount of elasticity of bundle occurs here, but nothing like that in $C$. Fendleri. The enormous amount of thick-walled parenchymatous storage tissues seems to have more effect in giving firmness to the internal structure than does turgor. The bundles have almost no supporting function, and are never well developed, appearing, in the widest part of a fair sized specimen, only $\mathrm{I}^{\mathrm{cm}}$ in thickness of xylem. The branches passing out to the tubercles or ridges divide through the tissues as in C. Fendleri.

The absorptive root contains numerous small crystals in the rays, more in proportion than appear in the stem. The chief xylem element is the scalariform tracheid; fiber tracheids also occur. In the anchoring root, as before, the proportions are reversed. The phloem is mainly composed of sieve tubes, but has a slight sclerenchymatous compressed sheath, a character which will be noted as fairly constant in both stem and root through the majority of forms.

Cereus giganteus Engelm.-The epidermis and hypoderma are both without crystals, the latter being exceedingly thick, of twelve to fourteen layers of cells. The assimilative tissue is of the usual elongated cells, the filamentous arrangement of which is extremely well marked, to such a degree even that the filaments in a preparation can be separated easily. Chlorophyll extends deep into the tissue, and the elongated character of cell is found for nearly $20^{\mathrm{mm}}$. The medullary tissue is thick-walled and pitted, containing starch in the immediate vicinity of the bundles. Mucilage, though present in quantity sufficient to hinder the staining of sections, is not very thick. There is, however, especially in the younger parts, a watery solution apparently identical with that seen in E. Wislizeni, but much stronger, causing the tissue upon exposure to turn almost immediately from white to pinkish, and then to a dark purple.

In bundle formation, the method described for $E$. Wislizeni above is carried to greater perfection. Here not only do the bundles join their xylem portions, but all those of a single rib are surrounded by one sheath, formed gradually. In a young stage it may be seen outside each separate bundle, later two or 
more bundles are embraced by a single sheath, and this process apparently continues until all the bundles of the rib are thus bound together. This sheath is not the ordinary one of compressed sclerenchyma so commonly found next the sieve tubes. This outer one seems to be a special structure, composed of the obliquely pitted fiber tracheid so often mentioned, which here inclines more than ordinarily to the tracheid form, with wide lumen and with the extremities of the cells scarcely pointed. The individual cells are much larger than those of the same nature found in the xylem. The ribs alternate with the ridges of tubercles, both undergoing more or less branching. A fullgrown rib, according to measurements taken from dead skeletons, seldom exceeds $3^{\mathrm{cm}}$ in thickness. The phloem has the usual development of sieve tubes; the xylem is made up almost wholly of scalariform tracheids, an element so far noted only in the root. Besides these, there also occur fiber tracheids, undoubtedly in increasing proportion as the size of the rib and the corresponding function as a support increases.

The absorptive root differs from the others described in having in the phloem an abundance of fiber tracheids, forming a wedge pointing outward, starting just outside the sieve tubes of each bundle. These cells are also numerous in the xylem, together with the scalariform tracheids. Crystals are common in the cortex as well as in that of the stem, and are large and closely aggregate. They do not seem to be entirely homogeneous, but take some foreign substance as a nucleus. At times they appear to grow by concretion, showing when viewed in optical section a series of concentric circles.

The necessity for a fibrous strengthening in the absorptive root of this large form can best be understood by examining the method of growth. In starting as a seedling, the plant begins life with a base slightly sunken in the ground, but far narrower than the heavy column which it is to support. Therefore, as this column develops, the whole becomes very top-heavy, and would certainly fall were slightly greater surface exposed to the wind. The anchoring root, at this time well developed, holds 
it firmly to the ground, but only to a slight degree prevents a swaying movement, easily induced, even in plants $\mathrm{I} .5^{\mathrm{m}}$ high, by comparatively little force. Hence to the large lateral roots, developed from the sunken base at a later period, is given the function of steadying the whole plant, in addition to their primary work of absorption.

Mamillaria Grahami Engelm. - The epidermis is free from crystals, but the one-layered hypoderma contains them in almost all its cells. The assimilative tissue is of small cells elongated, as usual, perpendicular to the surface. The colorless medullary portion is of thick-walled cells pitted as in E. Wislizeni and $C$. giganteus, and grades into the assimilative tissue. The lateral bundles can here be traced out into the tubercles. The stem bundles appear to start in a more or less wavy line, and to suffer fusion to some extent. There is comparatively little branching, but secondary medullary rays are occasionally found, and there is also a growth of the bundles in width, so that finally a rather compact cylinder is formed. As regards branching and internal structure of bundle, this species approaches $C$. Fendleri nearer than any of the others. The xylem is composed of alternating portions of spiraled ducts and tracheids of the flattenedspiral type, the latter being the more prominent. The phloem has a slight compressed sheath of sclerenchyma. Sieve tubes appear rather poorly developed, a thick-walled, somewhat elongated parenchyma taking up most of the region of the phloem.

In this small species there is apparently no distinction of anchoring and absorptive root systems. The bundle cylinder is compact, the pith practically absent, and the medullary rays reduced generally to a single cell layer. The phloem is slight and of sieve tubes. Outside the phloem, filling the small space between it and the cork cambium, is a parenchyma tissue of large rather thick-walled cells. The xylem consists chiefly of spiraled tracheids, with some amount of extra reticulation, and of smaller ringed ducts, the rings flattened inward, sometimes also bound together by extra spirals or reticulations. Crystals occur but 
seldom in the root, but are present in some quantity in the cortex and medulla of the stem.

Opuntia phaeacantha Engelm. - The hypoderma is rather thick, of six to eight layers, the outer one compactly filled with crystals, which occur also in great numbers throughout the assimilative and medullary tissues, clustering more or less about the bundles, but especially prominent in and about large ductlike spaces just exterior to certain of the bundles in both stem and root (Schumann's Krystalschläuche). Mucilage is fairly abundant. The assimilative cells are somewhat elongated, perhaps less so than in other forms so far recorded. Chlorophyll is deepest in the outer layers, but present as well in almost all parts of the deeper thin-walled parenchyma. The stem bundles form a loose reticulated network, branching early, especially on the flat surfaces of the stem, forming very wide secondary medullary rays. The phloem has the usual development with a sclerenchyma sheath. The xylem in early parts consists almost entirely of smaller annular ducts with flattened rings, but later forms spiraled tracheids and a large amount of obliquely pitted fiber tracheids.

In the root especially are seen the Krystalschläuche in a high state of development, with a diameter of almost $\mathrm{I}^{\mathrm{mm}}$. The crystals seem to be deposited mainly along the edges of the duct, which may serve also to some extent for the transfer of mucilage. The phloem of the bundle has a slight sheath; the xylem is composed of large and small scalariform tracheids and the usual fiber tracheids.

Opuntia fulgida Engelm. - The epidermis contains a deposit of crystals, a small quantity of which also occurs in the relatively thin hypoderma. The assimilative tissue is of cylindrical cells in lines, grading in the interior into large thin-walled parenchyma, also chlorophyllous. Mucilage is exceedingly abundant, and the ducts for its accommodation and transfer are both large and numerous. Large crystals, loosely aggregated, occur in small numbers throughout the tissue.

The bundles here remain very small through several joints, 
later becoming fused into a reticulated skeleton, the separate bundles of a single strand also anastomosing. The wavy line formation is seen to a slight extent in these Cylindropuntias also; there is apparently no branching, and little increase in width of bundle. The phloem presents no unusual characters;

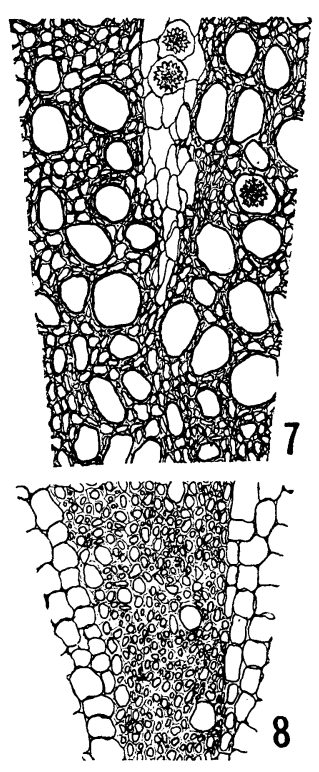

FIG. 7.-Cross sec. tion of portion of xylem from absorptive root of Opuntia fulgida.

FIG. 8.-Cross section of portion of xylem from anchoring root of Opuntia fulgida. the xylem is composed of annular ducts, with flat rings at regular intervals; later on there occur also spiral tracheids, with steps grading to the true trachea.

In an earlier article the roots of this species have been referred to as anchoring and absorptive. Portions of the xylem of each are figured here to show the difference in texture (figs. 7,8 ). In the absorptive roots the elements are wider, more regular, and less thickened. The phloem differs but slightly in the extent of development of sieve tubes; the xylem difers as usual in proportions of elements, consisting in both of scalariform tracheids and fiber tracheids. 'From the prominence of the latter, both here and elsewhere, it would appear that the main function, if not the only one, which this element performs in the Cactaceae is one of support.

Opuntia arbuscula Engelm.-The hypoderma is fairly thick, with a compact deposit of crystals in the outermost layer. The assimilative tissue is compact, the cells being small and greatly elongated in regions near the surface. The chlorophyll extends through the thin-walled parenchyma as well. Crystals are very abundant throughout, varying considerably in size and compactness of aggregation. The stem is very turgid and mucilaginous, kept rigid by turgor for some time, with late bundle development. The bundles finally form the same kind of reticulated skeleton seen in O. fulgida. The phloem is as usual; the 
xylem shows an occasional ringed duct, apparently an early element, but is principally composed of scalariform and fiber tracheids. Starch is present in considerable quantity through the stem.

The cortical parenchyma of the absorptive root is thickened in many places for storage purposes. The cells are filled with a thick mucilage, which aids in holding the water. A considerable deposit of starch, as well as of the regular calcium oxalate crystals, occurs in the medullary rays, but not at all in the cortex, an apparent differentiation of regions for various reserve substances. The phloem is of ordinary character, with a slightly developed sheath; the xylem is composed

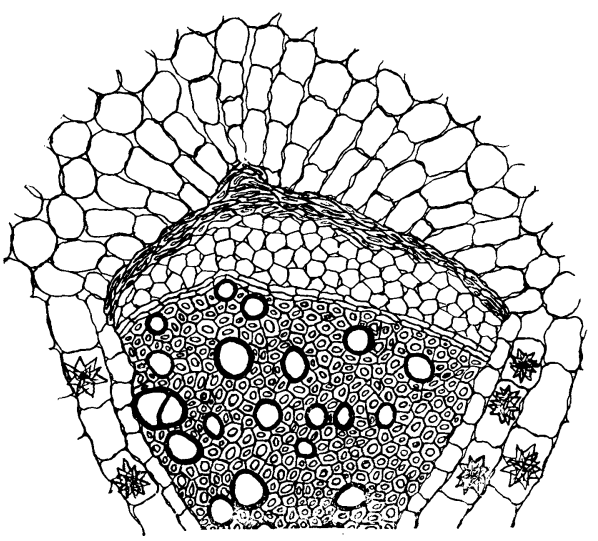

FIG. 9.--Portion of bundle from root of Opuntia arbuscula. mainly of scalariform tracheids of various sizes, but contains a few fiber tracheids as well. A rather peculiar phenomenon is presented by the convergence of the cortical tissue toward the center of the phloem. Whether this was to hasten transfer of materials between cortex and phloem in young stages, before the sheath was thickened, in a way analogous to the clustering of palisade about the leaf bundles, which so commonly occurs, is a question which at once suggests itself, but upon which I am able to throw no light at present ( $f i g .9)$.

Opuntia leptocaulis DC. - The epidermis contains crystals in cells specially enlarged to receive them. The hypoderma is of four or five layers, and the assimilative tissue is elongated very slightly. The parenchyma of pith and cortex is nearly colorless, thin-walled, and contains considerable starch, evidently of the translocation variety. This species is not so succulent as the majority, and has an earlier development of the bundles. A point in which it differs from all the rest examined is in its 
possession of a well-marked interfascicular cambium in the stem, allowing the medullary tissue to increase in proportion to the growth of the bundle, instead of having the bundle compress and supersede it, as is apparently the condition in the others. That even here this cambium is not so active as that of the bundle seems to be demonstrated by the fact that outside the phloem the sclerenchyma sheath still appears compressed, though to a less degree. The xylem is composed mainly of fiber tracheids, intermingled with which are scattering spiraled ducts. The ordinary Opuntia reticulation occurs together with the finer anastomosis of the bundles of a single strand. Between these closely connected unbranched bundles the medullary rays develop very thick walls, apparently lignified, and are so filled with a deposit of starch that in section they appear much more opaque than does the rather close-grained wood on each side of them. Mucilage occurs, but not so abundantly as in the majority of cases, and crystals of rather small size are scattered through all the parenchyma tissue.

The root does not materially differ from those already described. The cortical parenchyma is slightly thickened, and the xylem is composed of the scalariform and fibrous types of tracheids.

Summary and conclusion.- Several inferences may be drawn from the foregoing descriptions. In the first place, it will be seen that the roots, as regards branching and elements concerned, apparently undergo but slight variation, being composed, in almost all cases, of fiber tracheids and scalariform tracheids in the xylem, and of sieve tubes only in the phloem. To this general rule, as regards xylem portions, Mamillaria Grahami is the only exception among the forms here compared, and even in this the tracheid appears in greater prominence than the true duct. This exception, however, is enough to suggest that a more comprehensive examination will reveal more of a similar nature, and also perhaps disclose some links in the evolutionary chain between this and and the ordinary type.

In the stem, on the other hand, there is a great range of 
structural deviations, which seem to take place along definite lines and by definite steps. This variation extends to bundle branching and further reticulation, to the extent of succulence, character of parenchyma of pith and cortex, development of mucilage, and even to the kinds of elements composing the xylem of the bundle. In the phloem alone there is little change. The practically universal substitution of fiber tracheids for wood fibers, and the equally common appearance of tracheid elements in place of true ducts, except in early growth, points certainly to a general regression. The fiber tracheid, moreover, is variable in itself. In most cases it is quite sharply pointed and thick-walled, with a lumen, though broader than that of an ordinary wood fiber, still rather narrow. In a few instances, however, this same element loses its pointed character, widens its lumen still more, and except for its thick walls and oblique pits, scattered and exceedingly small, closely resembles an ordinary tracheid. This is very well shown in Cereus giganteus, a rather anomalous example, however, since here the fiber tracheid supplants a bast fiber instead of a wood fiber, and does not undergo an equal enlargement in the xylem portions of the bundle.

Crystal distribution and various storage peculiarities should be looked upon more as specific differences, I believe; likewise the thickness of hypoderma.

A word or two may be said of Opuntia leptocaulis. The early development of the bundles, the smaller degree of succulence, the persistent character of the leaves, at least in some varieties, as noted by Coulter, 7 the very slight elongation of the assimilative tissue, and above all the persistence of the interfascicular cambium, all tend to place this form in structure much nearer the ordinary dicotyledonous stem than any of the others examined. It seems safe to conclude that this species comes lower in the evolutionary line of adaptive modification than the rest of the Opuntias here mentioned, and may be considered nearer the primitive form.

${ }^{7}$ Contrib. U. S. Nat. Herb. $3: 456$. 
Perhaps the most striking results of any to be found here from the systematic point of view will be obtained by a comparison of the first three forms. Cereus Fendleri and Echinocactus Wislizeni are entirely dissimilar as regards character of medullary tissue, mucilaginous contents, firmness of interior structure, and especially in respect to arrangement and branching of bundles. The third form, Cereus giganteus, corresponds in all the above mentioned peculiarities, not with the other Cereus, as would be expected, but with the Echinocactus. So far as I can tell from plates, ${ }^{8}$ this closer resemblance to Echinocactus is carried out equally well in external characters, especially in those of the fruit, but to some degree at least in those of the spines and areolae (the last comparisons taken from living material). I have too little systematic knowledge of this group to contest the position of the species in classification, and can simply point to the fact that the two Cerei here mentioned belong at least to two different evolutionary branches within the genus, from one of which branches Echinocactus seems to have sprung.

The genus Cereus seems to me an especially fruitful field for the study of internal anatomy on a comparative basis. It is rather evident, from a hasty glance at the great variety of forms, that many different lines of development begin in this vicinity, lines which, though at present somewhat unraveled from external character, could at least be well subjected to confirmatory tests upon structural grounds. This would be of especial value in searching for the origin of the various other genera, the supposed offspring of this group.

It must not be thought, however, that I wish to give too great importance in classification to the internal anatomy, preferring it to the external characters. Its principal use is confirmatory. Too many internal variations spring up independently in several forms to make them alone sufficiently reliable. There must be some gradual internal metamorphosis, however, to correspond with the external. In what deep-seated organs this is shown, and what parts are more easily influenced by environmental

${ }^{8}$ Engelmann's Cact. Mex. Boundary. 
conditions, can best be determined by careful study. At present I am inclined to believe that the most permanent and satisfactory evolutionary characters will be found in the fibrovascular system. When its metamorphosis is fully understood a far clearer insight can be gained, not only into the interrelationships of these peculiar and at present much confused groups of plants, but also into the steps by which they became gradually accustomed to their present rigorous habitat.

Harvard University.

Later investigation shows that the statement (p. 42, line $\mathrm{I} 7 \mathrm{ff}$.) regarding periodicity of growth is incorrect. The smaller amount of growth noted was due to the drouth of the summer of I 900 . In spite of their storage facilities, these plants are apparently affected by temporary unfavorable conditions to a degree almost surprising. 